\title{
Research on Pricing Mechanism
}

\section{Pattern for China Electric Power Market}

\author{
Mian Xing \\ Institute for Theoretical Physics, North China Electric Power University, Baoding 071003, China \\ E-mail: hdxm01@126.com
}

\begin{abstract}
With the rapid development of global economy, people begin to pay more and more attention to the reform of electric power market. Under the background of China electric power market reform, in this article, we will research on the present power price patterns of China, i.e. two-parts power price and single power price, analyze their advantages and disadvantages, point out problems existing in the pricing on power network, put forward methods to solve these problems and establish good market environment for pricing on power network.
\end{abstract}

Keywords: Electric power market, Pricing on power network, Market environment

\section{Introduction}

\subsection{Actuality and characteristics of China electric power market}

With the unceasing reforms of China economy, essential changes has appeared in China electric power industry when the new century is coming, which are embodied from short supply to surplus supply of electric power. In order to actualize the sustainable development of electric power industry for a long term, the reform plan of "Factory and Web Separation, Pricing on power network" was put forward by China State Economic and Trade Commission in 1999. For China electric power industry, the core of this reform is the tremendous transformation of management concept which is changed from the haul pattern to marketing haul pattern. The 10th Five-year Plan of China Electric Power Development definitely put forward that the power price reform should be further deepened and the power price examination and approval should be reformed. According to the requirements of "Factory and Web Separation, Pricing on power network", the reasonable power pricing mechanism should be perfected and the legal supervision and management of power price should be strengthened. The "Factory and Web Separation, Pricing on power network" has become the general trends and urgent, but the relative discussions about how to pricing are still in dispute and there is no a recognized rule up to now.

\subsection{Difficulties encountered in power price reform}

As the experimental area, the Northeast of China has encountered many difficult problems in the practice, and the electric power market of Northeast was in logjam several times. To some extent, the difficulties of the electric power reform in Northeast include two linkage difficult problems, bottleneck of power system transmission and difficulty of capacity power price.

\subsubsection{Two linkage difficult problems}

Since the simulating operation was announced in 2003, the Northeast electric power market was trudging all along. And since the late of 2005, the Northeast electric power market was in logjam again, and even part power enterprises has retreated from the market up to now. The main reason of this logjam is the markup of coal and the linkage between coal and electric power can not follow it in time. In a healthy market, the markup of upper cost can be directly extended to lower cost. Whether the generation power dealers want to directly enhance trade quoted prices to digest coal costs or the linkage between coal and electric power is actualized through policies, which all directly induce the benefit cut of electric network enterprises, because the power sales price is fixed and the enhancement of power price must extrude the benefit space of power network. To keep the stabilization of pricing on power network in the regional electric power market for a long time, two linkages must be solved well, and one is the linkage between coal and electric power, and the other is the linkage between the price on power network and sales power price.

\subsubsection{Bottleneck of power network transmission}

The Northeast electric power market is the first regional market reform experimental region of electric power. This region involves three provinces and one region, i.e. Liaoning Province, Jilin Province, Heilongjiang Province and the East of Inner Mongolia. In fact, China took the Northeast as the first experimental region to implement regional electric power reform because the power supply of Northeast was relative rich and convenient for pricing on power network. However the electric power market of Northeast is mostly centralized in the south such as Liaoning 54 
Province, and because of the restriction of power network channel through which the electric power of north of Northeast is transmitted to the south, which induces furious competitions among power generation enterprises in province. When this situation is pushed to the regional electric power market, the original intention balancing regional electric power supply can not be actualized.

\subsubsection{Difficulty of capacity power price}

The pricing mechanism on power network implemented in China is divided into two sorts including two-part power price and single power price. At present, the pricing pattern competed between two-part power price and full power capacity price is implementing in Northeast. In the marketization operation of "Factory and Web Separation, Pricing on power network" for two-part power price, obvious limitations were founded. The system reform of electric power is in logjam, and the essential reason rests with the deficiency of theory and unreasonable system.

\section{Pricing pattern analysis of China electric power market}

\subsection{Advantages of pricing on power network}

The electric power industry is treated as the natural monopoly industry for a long time in China, so the public monopoly enterprises are established generally in this industry. However the low efficiency and bad service of monopoly enterprise induce the policy of "Factory and Web Separation, Pricing on power network" which means the power plants compete on the price on power network. After biding on power network, the competitions in the electric power industry among power plants have active influences on the developments of electric power.

2.1.1 Being propitious to establish modern enterprises system for the power plant, and making electric enterprises do well enterprise management according to market rule

Many jamming factors exist in the past pricing mechanism, and enterprises tried to make the reported prices in favor of themselves through many non production approaches, which decentralize much energy of enterprises. After pricing on power network, various power plants compete fairly, and which costs are low, which can obtain better benefits. Therefore, all power plants will actively adopt measures to reduce costs. For example, they adopt advanced management methods, decrease consumptions to enhance the economic benefits of the enterprise, reconstruct old facilities of power generation or introduce advanced facilities to enhance production efficiency, enhance operation abilities of employees. These measures can decrease the costs of enterprise, enhance the competitive power of enterprise, and make social resources optimized, avoid wastes, so when the power plants pursue their own benefits, they also increase the total welfare of the society.

\subsubsection{Eliminating the phenomena of lagged price}

After power plants implemented the pricing on power network, the power price will be changed with the change of production management costs of power plant. When the price of coal rises, the power generation will increase and the power price will rise with it. When the supply of power generation is bigger than demand, the price on power network will decrease, here, the power plants with higher production costs will take various measures to reduce production costs and finally make the power price achieve the marginal cost of the power plant.

\subsection{Present power pricing pattern of China and its advantages and disadvantages}

The price mechanism is the core of market mechanism, and the intention of "Factory and Web Separation, Pricing on power network" is to clear the price mechanism of electric power market. The direction of electric power reform is to establish reasonable price mechanism to adapt the change of electric power market as soon as possible. The pricing mechanism implemented in China includes two-part power price and single power price.

\subsubsection{Rule of two-part power price}

The two-part power price consists of the price on power network and power capacity price. The power capacity price is constituted by marginal cost and a few incomes, which is decided by the changeable costs and reasonable incomes. The power plants with different power qualities pay different capacity prices according to their sorts and same sort plant has same power capacity price. The two-part power price can make power generation enterprises possess power generation capacity and obtain stable capital yields, and store more spare capacity for power network and offer reliable capacity guarantees for the security of the power network. Because it can offer stable yields, its price mechanism is welcomed by investors and extended by the theory horizon. But in the marketization operation of pricing on power network, some certain problems appeared. The two-part power price makes against mutual power purchase among networks, the combination of middle-sized and small-sized power plants, and the apex-adjustment of power network.

\subsubsection{Rule of single power price}

The single power price is the price of the electric power that enterprises supply in certain range according to market demand and their own costs, which is based on the social average price of all power generation enterprises 
computed according to long-term marginal cost method. The single power price is abroad applied in practice because of its simple operation and balance.

The two-part power price and single power price mutually exist according to their own advantages and disadvantages, respectively adapt certain range, but with the strengthening of competition and the perfection of electric power market, the two-part power price will be extended abroad.

\subsection{Establishing market environment for pricing on power network}

For the market economy in the electric power market, the market patterns of electric power competition are different. When the market function is emphasized, the directional function of plan must be seen. To make pricing on power network operate normally, the following works must be implemented.

\subsubsection{Power network planning}

The essential of power network planning is to establish uniform and open electric power market with higher efficiency of power distribution, and make various market principal parts can compete fairly in the electric power industry. At present, the China power network is divided into six regional power networks, and effective interconnection is implemented among these six regional power networks. After the implementation of "Factory and Web Separation, Pricing on power network", the construction of interconnection among regional power networks in whole China becomes especial important. Only under the premise of effective interconnection of network in the whole country, the electric power market can be established, and optimized distribution of electric power resources can be realized, accordingly the total economic benefits of electric power industry can be enhanced. Therefore, one of important contents of present electric power system reform is to do power network planning well.

\subsubsection{Fluctuant prices}

The pricing on power network requires not only the generation power side implements bidding, but also the power price of demand side should correspondingly change with it, and both the incomes and risks obtained in the pricing on power network should be assumed by consumers. Only in this way, the normal operation of pricing on network can be ensured. Contrarily, the electric power crisis such as in US California will occur again.

\subsubsection{Flexible policies}

On a fair platform, the competition is fair to most power generation enterprises, which is helpful to enhance enterprise efficiency, reduce costs, and make power price return to the average level recognized by the society. However, it makes against the development of special power generation enterprises such as thermal power plant, wind power plant and garbage-cremation power plant and so on. To these enterprises, they must follow the pricing mechanism, and the government should not treat them differently for the power price, or else, which will influence the normal operation of pricing mechanism. However, if the government wants to support the developments of these enterprises, they can derate their revenues and fees, or offer allowances according to their power generation capability. The pattern reform of governmental management and treatment on electric power should combine enterprise reform, government reform and system reform.

\section{Conclusions}

The above discussion is the analysis to the pricing mechanism of electric power market, which is summarized through consulting and analyzing references and present actual situations. Under the reform plan of "Factory and Web Separation, Pricing on power network" in electric power market, in this article, we research on the present power price patterns of China, i.e. two-parts power price and single power price, analyze problems existing in the pricing on power network, put forward methods to solve these problems and establish good market environment for pricing on power network.

\section{References}

Carlos Vazquez, Michel Rivier, Ignacio J PE rez-Arriaga. (2001). If Pay-as-Bid Auctions Are not a Solution for California, then Why Not a Reliability Market. Elsevier Science Inc. May 2001.

Guoqiang, Zhang, Yunzhou \& Lvjian. (2005).Study on Scheme for Structure and Construction of Synchronous Power Grid in China from 2010 to 2020. Power System Technology. No.11. p.14-16.

Kahn Alfred E, Cramton Peter C, Porter Robert H, et al. (2001). Uniform Pricing or Pay-as-bid Pricing: a Dilemma for California and Beyond. The Electricity Journal. 14 (6). p.70-79.

Liu, Jichun. (2004). Operation System of Electric Power Market. Beijing: China Power Press. p.7-9.

Liu, Manping. (2005).Price Argument between Coal and Electricity Needs Marketed Operation. Electric Power. No.3. p.1-4. 
Maojin. (2006). Regional Power Market Construction's Latent Worries. China Power Enterprise Management. No.1. p.24-27.

Wang, Xiangqin \& Liu, Minshan. (2002). Manual of Electric Power Marketing and Management. Beijing: China Power Press. p.125-127, 371-382, 479-488.

Zhang, Lizi \& Zhenghua. (2004). Power Price Mechanism of Regional Electric Power Market. Beijing: China Power Press. p.84-98. 